\title{
К вопросу о резервировании генерирующих мощностей
}

КОВАЛЁВ Г.Ф., доктор технических наук, КРУПЕНЁВ Д.С.,

ЛЕБЕДЕВА Л.М., кандидат технических наук,

Институт систем энергетики им. Л. А. Мелентьева (ИСЭМ) СО РАН, Иркутск.

E-mail: kovalev@isem.irk.ru

В статье, которая носит дискуссионный характер, авторы делают акцент на тесной взаимосвязи балансовой надежности и полного резерва мощности электроэнергетической системы. Обращается внимание на необходимость нормирования уровня надежности электроснабжения в рыночных условиях. Ключевые слова: балансовая надежность, полный резерв мощности, вероятность, норматив, территориальная зона, пропускная способность ЛЭП, располагаемая мощность генерации

Продолжая развитие поднятой «ЭКО» темы резерва энергетических мощностей и в противовес высказанной автором [1] точке зрения о том, что эта проблема требует решения, прежде всего, в экономическом, а не в техническом аспекте, мы считаем, что для ее решения требуется комплексный технико-экономический подход к обеспечению надежной и эффективной работы отечественной электроэнергетической системы.

\section{Подходы к нормативам резервов энергомощностей}

В современных условиях функционирования и развития Единой энергосистемы (ЕЭС) России проблема резервирования генерирующих мощностей приобрела особую остроту, чему способствовали следующие основные причины [2-4]:

- из-за кризиса в экономике России в Единой энергосистеме образовались большие избытки установленных генерирующих мощностей, в значительной части выработавших свой ресурс, а потому недостаточно надёжных, но числящихся на балансе и требующих расходов на содержание;

- несмотря на наличие избытков мощности в целом по ЕЭС, надежность в отдельных региональных энергоузлах неудовлетворительна;

- недостаточное внедрение современной диагностики оборудования при организации ремонтов в энергокомпаниях; 
- несоответствие принятой модели рынка мощности и электроэнергии современным реалиям функционирования ЕЭС России, в том числе отсутствие стимулирующих замещение устаревших мощностей механизмов, и др.

С учетом изложенного ответ на вопросы о том, каким должен быть уровень резервирования генерирующей мощности и какое ее размещение в системе наиболее эффективно, зависит от таких факторов, как технические характеристики используемого генерирующего оборудования, возможности сетей по передаче мощности и электроэнергии, требования потребителей по обеспечению необходимого уровня надежности их электроснабжения и др. Достаточный уровень резервирования электроэнергетических систем (ЭЭС) важен для экономики каждого региона и страны в целом, так как развитие отраслей, особенно энергоемких, во многом зависит от надежности их электроснабжения.

Завышенный уровень надежности вызывает дополнительные издержки, которые перекладываются на потребителей электроэнергии, а недостаточная надежность приводит к ущербам как у потребителей, так и у энергетических компаний. Поэтому решение задачи оптимального резервирования в электроэнергетике должно опираться на обоснованный научный подход с использованием специализированных программных продуктов для анализа надёжности.

В 1990-2016 гг. коэффициент использования установленной мощности в ЕЭС России сократился с 58 до 47\% [2]. Избыток мощности в энергосистемах доходит до 30-40\% от максимума нагрузки. Так называемая вынужденная генерация за последние годы привела к двукратному росту издержек, которые приходится компенсировать конечным потребителям. Так, только в 2015 г. им пришлось дополнительно заплатить 19 млрд руб.

Обеспечение надёжного снабжения потребителей электроэнергией является приоритетной задачей при управлении ЭЭС. При этом нормирование показателей надёжности используется на всех этапах функционирования и во всех иерархических уровнях энергосистемы. Создание комплексных взаимосогласованных (непротиворечивых) нормативов надежности для всех территориальных и временных уровней управления технологическими звеньями ЭЭС и установление характеристик надежности - это сложная научно-техническая и организационная задача, для решения которой требуется объединение усилий большого числа специалистов разного профиля (техники, математики, экономисты, финансисты, юристы) из многих организаций - научноисследовательских, проектных, эксплуатационных, правительственных, законодательных, страховых компаний и т.д. Форма экономических отношений в обществе, качество жизни (чем богаче страна, тем выше нормативы надежности), особенности формирования ЭЭС и их объединений - всё это оказывает влияние на систему нормативов и объясняет различие нормативов надежности в разных странах и энергокомпаниях [5].

Нормирование надежности в электроэнергетике имеет длительную историю. Все нормы и стандарты, как правило, фиксируются в директивных материалах (руководящие указания, правила устройства и эксплуатации, СНИПы, справочники, циркуляры, стандарты организаций и т.п.). Возможно также формирование документов, посвященных исключительно нормативам надежности объектов ЭЭС различных уровней. Эти нормативы периодически подвергаются пересмотру в связи с изменениями внешних и внутренних условий функционирования ЭЭС и ее элементов, например, форм собственности, появлением новых оборудования и технологий, разработкой новых методов и средств управления, подходов к проблеме надежности и т.д.

Если говорить о достаточно полной и взаимоувязанной системе нормативов в электроэнергетических системах, то следует отметить, что проблема до сих пор не нашла приемлемого решения. По составу нормативов надежности в ЭЭС среди специалистов имеются разные мнения. Одни считают, что нормирование надежности должно сводиться к выбору и количественной оценке минимального числа показателей надежности, и даже всего одного - вероятности бездефицитной работы ЭЭС. Другие высказываются за то, чтобы регламентированы были и прямые характеристики, и косвенные «правила надежности», процедуры принятия решений по надежности ЭЭС и вычислительные модели для расчетов надежности, а также расчетные схемы, условия и исходные данные. Примером такого подхода могут служить стандарты надежности для крупных энергосистем Северной Америки [6, 7].

В практике управления энергосистемами ряда иностранных государств для обеспечения их надёжности применяется 
вероятностный подход и используются нормативы вероятностных показателей надёжности [6]:

- во Франции критерием балансовой надёжности служат значения показателя надёжности LOLH (loss of load hours) - ожидаемое число часов в году, в течение которых возникает дефицит мощности. Считается, что ЭЭС работает надежно, если LOLH не превышает трех часов в год;

- в Нидерландах нормированное значение LOLH составляет четыре часа в год;

- в скандинавских странах критерием надежности энергосистемы является LOLP (loss of load probability) - вероятность дефицита мощности на малом интервале времени, как правило, в период максимальной нагрузки, который равен $0,001 \%$ в год;

- в США принят норматив LOLE (loss of load expectation) 0,1 день в год.

В принципе, подход к нормативам надежности должен меняться на разных временных и территориальных уровнях управления ЭЭС. Так, при прогнозировании развития на 15 и более лет вперед возможно использование численных нормативов надежности и резервирования генерирующей мощности и пропускных способностей связей, с применением примитивных моделей их определения, поскольку более точное решение и невозможно (из-за большой неопределенности условий развития), и нецелесообразно. На этом этапе решения носят предварительный (прогнозный) характер. Значения нормативов должны обеспечивать ориентировочную оценку генерирующей мощности и пропускных способностей связей на базе выбранного принципа обеспечения надежности (самобалансирование региональных энергокомпаний, либо использование всех системных эффектов ЭЭС, либо что-то другое).

Также следует учитывать то, что при планировании и проектировании на следующих временных этапах управления развитием ЭЭС (энергокомпаний) (на 10-15 и 5-10 лет) неизбежны уточнения. На последнем этапе, отталкиваясь от заданных нормативных значений, необходимо осуществить технико-экономическую оптимизацию величины и резервов генерирующих мощностей, их размещения по энергорайонам (объединениям и регионам) и энергокомпаниям, конфигурации и параметров связей с учетом возможных технических и инвестиционных ограничений. Поскольку принятие решений на данном заключительном этапе является окончательным перед началом их практической реализации, что связано впоследствии с реальными затратами значительных материальных ресурсов, то здесь оправданны практически любые издержки на обосновывающие расчеты, а опора только на нормативы по надежности на этом этапе может привести к выбору недостаточно эффективного варианта развития ЭЭС.

Балансовая (системная) надежность электроэнергетических систем и резервы генерирующей мощности (и их нормирование) тесно взаимосвязаны. Более высокий показатель балансовой надёжности - вероятность безотказной (бездефицитной) работы - определяется бо́льшим резервом мощности. При этом речь должна идти о резерве располагаемой мощности (без учета «разрывов» мощности). Целесообразнее рассчитывать и принимать норматив балансовой (системной) надёжности (вероятность бездефицитной работы) ЭЭС, который и будет определять величину необходимого резерва мощности.

\section{Нормирование надёжности в ЕЭС России на современном этапе}

На сегодняшний день утвержденных нормативов показателей балансовой надежности для ЕЭС России нет, имеются лишь рекомендательные значения вероятности безотказной (бездефицитной) работы потребителей, прописанные в «Энергетической стратегии России 2030» и в [8]. В соответствии с данными документами Единая энергосистема России в 2030 г. должна обеспечивать вероятность безотказной работы потребителей электроэнергии на уровне 0,9997. Причем имеются два промежуточных этапа-это 2015 г. и 2020 г., по достижении которых вероятность безотказной работы должна быть на уровне 0,999 и 0,9991 соответственно, при этом не указано, как трактовать данный норматив: для ЕЭС в целом или для расчетных узлов системы.

Нормативный показатель балансовой надежности на уровне основной структуры ЕЭС России (расчетных энергоузлов ЕЭС и межсистемных связей) - вероятность бездефицитной работы, равная 0,996. Данный показатель обоснован в [9] для условий функционирования и развития энергосистемы СССР.

Исходя из зарубежных публикаций, уровень нормирования надежности ЭЭС определяется эффективностью экономики соответствующего общества (страны). Россия на данном этапе 
имеет статус развивающегося государства, поэтому норматив балансовой надежности (вероятность безотказной (бездефицитной) работы Р>0,996) может оказаться для нее непосильным. Вопрос о его увеличении следует отложить до лучших времен, а пока ориентироваться на 0,996 .

Для 2017 г. надёжность электроснабжения в некоторых регионах неудовлетворительная и даже очень низкая. И это несмотря на наличие избытка генерирующих мощностей по ЕЭС РФ в целом. Поэтому превышение фактического значения вероятностей бездефицитной работы Р для многих подстанций (центров питания), питающих распределительные сети, показателя 0,996 следует признать нормальным. А для тех регионов, где нормативный показатель $\mathrm{P}$ для подстанций, питающих распределительные сети (110 кВ и ниже), будет меньше 0,996 , следует проводить соответствующие мероприятия по его достижению нормативного уровня $(0,996)$.

Считается, что норматив должен быть единым для страны в целом. Если же принять, что для каждой территориальной зоны существует и свой норматив балансовой надежности, обосновывая это так называемым «рыночным подходом», то, в конечном счете, это станет образцом несправедливости (где-то надежность электроснабжения ниже, а где-то - выше). О каком нормативе тогда может идти речь? Если же где-то показатель балансовой надежности Р окажется выше 0,996 , о чем было сказано, то это просто «счастье» энергетической компании соответствующей территориальной зоны.

Мероприятия по повышению показателей балансовой надежности и резерва должны включать две составляющие.

Первое и наиболее важное - обеспечить резерв и поднять уровень балансовой надежности там, где она ниже норматива, но для этого надо четко знать, где это происходит. Поэтому определение территориальных зон в модели ЕЭС для расчетов балансовой надежности является весьма ответственной операцией. Число территориальных зон должно быть не меньше числа административных субъектов РФ. Но поскольку внутри таких зон возможны энергорегионы, связи которых с остальной системой слабы, то должна быть проведена тщательная работа по формированию расчетной схемы ЕЭС с выделением зон равной надежности (зон свободных перетоков), которые, как уже давно принято, замещаются в схеме так называемыми «концентрированными» узлами. Внутри этих зон принимается, что пропускные способности связей обеспечивают все возможные перетоки мощности во всех возможных режимах (нормальных, ремонтных, аварийных).

Второе - реализация резерва, в том числе выбор размещения и вида резервов, а также исключение запертой мощности. Для расчетов и оценки балансовой надежности должна быть создана (или взята, если есть) имитационная модель ЕЭС, в которой были бы учтены все факторы, влияющие на надежность: уровни и размещение нагрузок, генерирующих мощностей, пропускных способностей связей; энергетические и надежностные параметры оборудования; учет существующих норм на проведение различных видов ремонтов оборудования (текущих, средних, капитальных, на модернизацию, реконструкцию, техперевооружение и пр.) [10].

Если принять за основу нормирование балансовой надежности, то обеспечение ее норматива, как уже отмечалось, «автоматически» в процессе расчета определит значение и схему размещения генерирующей мощности в ЕЭС. Следовательно, их дополнительное нормирование не требуется. При этом нормы на проведение плановых ремонтов задаются в исходных данных для расчета. Необходимая величина полного резерва мощности является результатом расчета балансовой надежности, так же как и необходимые запасы по пропускным способностям связей. При этом нельзя резерв, полученный в результате оптимальных расчетов балансовой надежности, называть нормативным. Это - резерв мощности, необходимый для обеспечения нормативной балансовой надежности. И лучше использовать традиционный термин - полный резерв мощности - вместо ныне предлагаемого «суммарного».

Полный резерв мощности включает в себя резервы на компенсацию мощностей, выводимых в текущий и капитальный ремонт и т.д., а также оперативный резерв для компенсации мощности, аварийно выходящий из работы, и для регулирования частоты (так называемые стратегический и коммерческий резервы рассматриваются отдельно, см. $[4,11])$.

При выборе размещения величины резервов мощности в системе следует определять, какой вид резерва требуется (на ГЭС, на ТЭС, ГТУ, ПГУ и т.д.).

Что касается выбора абсолютных или относительных величин, то нужно и то и другое, в зависимости от решаемой задачи.

6 ЭКО. - 2017. - № 11 
Относительная величина резерва генерирующей мощности должна соотноситься с регулярным годовым максимумом нагрузки соответствующего энергорегиона или ЕЭС в целом, а не с установленной мощностью генерации.

Процессы оптимизации полного резерва генерирующей мощности, а также запасов пропускных способностей связей в рамках обеспечения норматива балансовой надежности должны выполняться одновременно с учетом экономических характеристик их сооружения и эксплуатации.

Если же принимается решение нормировать не балансовую надежность, а полный резерв, то тогда никаких расчетов на модели ЕЭС не требуется, и можно обойтись экспертными оценками. Одновременное нормирование и показателя балансовой надежности, и всех видов резервирования генерации, кроме норм на ремонты (да еще и без увязки с пропускными способностями связей), невозможно. Надо выбирать что-то одно. По мнению авторов, предпочтение следует отдавать балансовой надежности.

\section{Проблемы сбора и обработки исходных данных}

От полноты и достоверности исходной информации зависят получаемые показатели балансовой надёжности ЭЭС и, соответственно, размещения резервов мощности. Ниже дан анализ основных принципов сбора исходных данных и проблем, которые возникают при сборе информации.

А. Расчетная схема ЭЭС (эквивалентные энергоузлы и связи между ними) должна быть составлена таким образом, чтобы каждый энергоузел, представленный в ней, был концентрированным, т.е. внутри узла не должно быть ограничений на перетоки мощности в любых вероятных режимах.

Б. Характеристика генерирующего оборудования в расчетHblx yзлах ЭЭС. Для проведения оценки балансовой надежности ЭЭС необходимо иметь следующую информацию: состав генерирующих агрегатов в узлах системы, единичную располагаемую мощность, норматив на проведение плановых (капитальных, средних и текущих) ремонтов, аварийность каждого агрегата.

При проведении исследований надежности современных отечественных ЭЭС были выявлены следующие проблемы: информация по суммарной располагаемой мощности узла в источниках различается. Отсутствуют данные по аварийности генерирующих агрегатов. Так, в отчетных данных приведен показатель «Суммарное время нахождения в ремонте (плановый, неплановый) за отчетный год, часы», из которого трудно выяснить, какое время агрегат был в плановом ремонте, поэтому необходимо обязать генерирующие компании корректно разделять плановые и неплановые ремонты в отчетных данных.

В. Информация о графиках нагрузки в узлах ЭЭС. Для проведения исследования необходимо иметь характерные суточные почасовые и годовые графики месячных максимумов нагрузок в каждом из узлов, среднеквадратические отклонения нагрузок от прогнозируемых графиков.

При составлении расчетной схемы ЭЭС на основе кластеризации границы некоторых узлов не будут соответствовать границам, в которых находятся региональные энергосистемы, поэтому для оценки балансовой надёжности для подобных схем необходима дополнительная информация о графиках нагрузки этих узлов.

\section{Заключение}

В современных условиях функционирования Единой энергосистемы России возникли проблемы, снижающие ее эффективность. Одна из них - необоснованные избытки генерирующей мощности, приводящие к неэффективной работе ЕЭС, к повышению стоимости электроэнергии для потребителей и другим негативным последствиям.

Чтобы избежать этого, предлагаем следующее.

1. Целесообразно нормировать балансовую надежность, а не резервы генерирующих мощностей. Это связано как с общепринятой практикой (в том числе зарубежной), так и с тем, что норматив балансовой надежности определяет и необходимый резерв генерирующей мощности, и его размещение в системе с учетом пропускных способностей межсистемных связей*.

2. Сейчас в РФ наблюдается избыток мощностей, а, соответственно, и высокий уровень балансовой надежности в большинстве региональных энергосистем. Но есть отдельные энергорайоны, где расчетные уровни балансовой надежности низкие (ниже 0,996). Рекомендуется, приняв необходимый норматив (например, 0,996),

* В данном случае авторы считают первичным для оценки надежности, а следовательно, и резервов, наличные «пропускные способности межсистемных связей» (Прим. ред.). 
добиваться его выполнения там, где показатель ниже, не снижая эти показатели там, где они на данный момент выше.

3. Точность расчетов в значительной степени определяется качеством исходной информации. Требуется большая работа для создания на федеральном уровне инфраструктуры сбора и обработки первичной информации о параметрах функционирования ЭЭС и оборудования. Это будет способствовать повышению обоснованности принимаемых решений по обеспечению балансовой надёжности и необходимых для этого объемов и размещения резервирования генерирующих мощностей и запасов пропускных способностей связей.

\section{Литература}

1. Воронов Ю.П. Резервы энергетических мощностей: еще одна бездонная бочка. - ЭКО. - 2017. - № 9. - С. 125-143.

2. Восканян Е. Сколько стоит надежность? // Энергетика и промышленность России. - 2016. - № 08 (292).

3. Крупенёв Д.С., Пержабинский С.М. Алгоритм оптимизации надёжности электроэнергетических систем с использованием математического ожидания двойственных оценок // Управление большими системами. Вып. 54. - М.: ИПУ РАН, 2015. - С. 166-178.

4. Надёжность электроэнергетических систем / Ковалёв Г. Ф., Лебедева Л.М. - Новосибирск: Наука, 2015. - 224 с.

5. Ковалёв Г.Ф., Крупенёв Д.С., Лебедева Л.М. Ключевые аспекты нормирования системной надёжности ЭЭС (мировой и отечественный опыт) / Методические вопросы исследования надёжности больших систем энергетики. - Вып. 60 / отв. ред. Н.И. Воропай, А.И. Таджибаев (ПЭИПК) 2010: изд. ПЭИПК - СПб.: Северная звезда, 2010. - С. 36-51.

6. Reliability Standarts for the Bulk Electric Systems of North America. - NERC, 2008. - $1010 \mathrm{p}$.

7. Кучеров Ю.Н., Фёдоров Ю.Г. Развитие нормативного и методического обеспечения надёжности сложных энергосистем и энергообъединений в условиях либерализованной энергетики // Электро. Электротехника, электроэнергетика, электротехническая промышленность. - 2010. № 6. - С. 2-11.

8. Методические рекомендации по проектированию развития энергосистем / СО 153-34.20.118-2003. Утв. приказом Минэнерго России от 30.06.03 № 281 э.

9. Маркович И.М. Режимы энергетических систем. - М.: Наука, 1986. 252 c.

10. Справочник по проектированию электрических сетей / под ред. Д.Л. Файбисовича. - 4-е изд., перераб. и доп. - М.: ЭНАС, 2012. - 376 с. 11. Концепция обеспечения надежности в электроэнергетике / Отв. редакторы: Н.И. Воропай, Г.Ф. Ковалёв. - М.: ИД «Энергия». - 364 с. 